\title{
Intravascular persistence of Anaplasma platys, Ehrlichia chaffeensis, and Ehrlichia ewingii DNA in the blood of a dog and two family members
}

\author{
Edward B Breitschwerdt ${ }^{\text {* }}$, Barbara C Hegarty ${ }^{1}$, Barbara A Qurollo ${ }^{1}$, Tais B Saito ${ }^{2}$, Ricardo G Maggi ${ }^{1}$, Lucas S Blanton ${ }^{2}$ \\ and Donald $\mathrm{H}$ Bouyer $^{2}$
}

\begin{abstract}
Background: Anaplasmosis, caused by Anaplasma phagocytophilum and Anaplasma platys, and ehrlichiosis, caused by Ehrlichia chaffeensis, Ehrlichia ewingii, the "Panola Mountain Ehrlichia" and Ehrlichia muris-like pathogens have been identified as emerging tick borne infectious diseases in dogs and human patients. Persistent intravascular infection with these bacteria is well documented in dogs, but is less well documented in human beings.

Methods: Serology and PCR targeting multiple microbial genes, followed by DNA sequencing, was used to test sequential blood samples. Tissue culture isolation was attempted in two laboratories.

Results: A. platys, E. chaffeensis, and E. ewingii DNA was amplified from two Anaplasma and Ehrlichia seronegative family members and their dog, all lacking typical symptoms of anaplasmosis or ehrlichiosis. Following treatment with doxycycline, the dog and mother were Anaplasma and Ehrlichia spp. PCR negative.

Conclusions: Sequential PCR testing provided molecular evidence supporting intravascular persistence of A. platys and Ehrlichia spp. in two humans and their dog. Diagnosticians and clinicians should consider the potential for co-infections due to these tick borne organisms.
\end{abstract}

Keywords: Anaplasma, Ehrlichia, Rickettsemia, PCR, DNA sequencing

\section{Background}

Anaplasmosis, caused by Anaplasma phagocytophilum and A. platys, and ehrlichiosis, caused by Ehrlichia canis, E. chaffeensis, E. ewingii, E. muris and the "Panola Mountain Ehrlichia", are emerging infectious diseases affecting dogs and human patients in North America and other parts of the world [1-3]. Canine vector borne diseases (CVBDs), including co-infections with more than one CVBD pathogen, are common in dogs, particularly those with frequent or constant vector exposure to varied tick species [4-6]. Among various animal species, including humans, Anaplasma and Ehrlichia spp. can induce acute, self-limiting or fatal infections, while persistent non-clinical infections often occur in dogs [7-9]. Following tick transmission, dogs

\footnotetext{
* Correspondence: ed_breitschwerdt@ncsu.edu

IIntracellular Pathogens Research Laboratory and the Center for Comparative Medicine and Translational Research, College of Veterinary Medicine, North Carolina State University, Raleigh, NC, USA

Full list of author information is available at the end of the article
}

can remain infected with $A$. phagocytophilum, A. platys, E. canis, E. chaffeensis, and E. ewingii for months to years, prior to immunological or therapeutic elimination of the infection or the development of chronic debilitating disease manifestations [7-9]. Dogs are natural hosts for A. platys, $E$. canis and potentially $E$. ewingii, but are considered opportunistic hosts for other Anaplasma and Ehrlichia spp. [6,7]. Persistent E. chaffeensis $[10,11]$ and $E$. canis $[12,13]$ human infections have been suspected previously. Recently, $A$. platys DNA was PCR amplified from blood samples collected from a veterinarian one month apart [14]. With the advent of PCR testing, reports of long-term Anaplasma and Ehrlichia human blood borne infections may become more common.

The data in this manuscript was generated after a physician requested to be entered into a Bartonella sp. research study. At time points spanning a six-month period, blood, buffy coat and inoculated cell cultures from members of the household, tested by PCR and 
sequencing, identified combinations of $A$. platys and Ehrlichia species. Anaplasma platys, E. chaffeensis, and $E$. ewingii DNA was amplified and sequenced from the dog, the physician and her daughter's blood, but not from two other household members.

\section{Methods}

\section{Patients and clinical presentation}

In September 2011, a 57-year-old-female physician requested to be entered into an IRB approved research study (North Carolina State University, 164-08-05), investigating the prevalence of Bartonella sp. bacteremia in various patient populations. In 2008, the woman had developed intermittent subcutaneous edema and mildly increased liver enzyme activities. Her 16-year-old daughter, adopted from China at 6 months of age, had been healthy until 2008, after which she developed upper body muscle pain requiring treatment by a physical therapist. Between 2008 and 2011, both mother and daughter were examined by several specialist physicians; neither had symptoms or hematological abnormalities (thrombocytopenia) consistent with anaplasmosis or ehrlichiosis; and both were HIV negative.

In 2008 the family purchased a 15-week-old male Papillon from a Chicago pet store. The puppy originated from a Missouri breeding facility, a region endemic for tick borne E. chaffeensis and E. ewingii. Due to an acute illness, the puppy was hospitalized hours after purchase; pneumonia was diagnosed radiographically and an extended hospitalization period was required to effectively treat the pneumonia. Subsequently, aggressive behavior was observed, resulting in occasional bites of the mother and daughter but not the other household members. In 2012, the dog was diagnosed with microvascular dysplasia, a congenital, developmental abnormality common in small breed dogs, that can contribute to hepatic dysfunction and behavioral abnormalities, potentially explaining the tendency for the dog to bite.

\section{Bartonella alpha proteobacteria (BAPGM) enrichment blood culture/PCR}

In accordance with a prior study [15], three sample sets were collected within a 7-day period to enhance detection of Bartonella spp. DNA using the BAPGM platform. Using blood aseptically collected on Monday, Wednesday and Friday (mother in September 2011, December 2011 and January 2012), (daughter in January and February 2012) and (dog in December 2011 and January 2012), Bartonella spp. serology and BAPGM (Bartonella alpha Proteobacteria growth medium) enrichment blood culture testing for Bartonella spp. was performed, according to previously published protocols $[15,16]$.

\section{Buffy coat preparation}

After the initial PCR amplification of E. chaffeensis DNA from the mother's blood in September 2011, aseptically obtained ethylenediaminetetraacetic acid (EDTA)-anticoagulated whole blood was processed in two formats (whole blood and buffy coat cells) in an effort to increase Ehrlichia sp. PCR sensitivity. Blood samples (mother, January, February and March) and (daughter, father and grandmother, March only) were sent concurrently to the NCSU-IPRL and UTMB for parallel tissue culture isolation attempts.

\section{Anaplasma/ehrlichia conventional PCR assays}

Genomic DNA was extracted using either the QIAsymphony SP (Qiagen, Valencia, CA) or the DNeasy Blood \& Tissue Kit (Qiagen, Valencia, CA) as per manufacturer recommendations. Each DNA extraction process included several negative control non-infected blood samples. To avoid DNA contamination of samples, DNA extraction and PCR sample preparation were performed in a room separate from the PCR amplification and gel analysis rooms, with a unidirectional work flow. Previously described Anaplasma and Ehrlichia $16 S$ rRNA gene conventional PCR (cPCR) assays were used to test whole blood, buffy coat and cell culture supernatant fractions prepared from the mother, father, daughter, grandmother and dog $[17,18]$. Amplifications were performed in a Mastercycler EPgradient $^{\oplus}$ aluminum block thermocycler (Eppendorf, North America). GEPs and GEPr and GEPs and GEP1060r primers were used respectively, to amplify 420 and 973bp segments of the $16 \mathrm{~S}$ rRNA gene [17] using Ehrlichia canis DNA as a positive control. Subsequently, newly introduced or derived (sodb) PCR assays were used by a blinded IPRL researcher to target the A. platys $p 44$ gene, E. chaffeensis and E. ewingii p28 genes, and Ehrlichia spp. $s o d b$ gene in blood and cell culture supernatants. Primers and cPCR conditions are provided in Table 1. Amplicons were assessed by electrophoresis of $8 \mu \mathrm{l}$ of each product in $2 \%$ agarose gels containing ethidium bromide. DNA extraction and PCR negative controls remained negative throughout the study.

\section{DNA sequencing}

Amplicons were sequenced directly or cloned into plasmid pGEM-T Easy Vector System Promega (Madison, WI) by GENEWIZ Inc. (Research Triangle Park, NC). Sequences were aligned and compared with GenBank sequences using AlignX software (Vector NTI Suite 6.0, InforMax, Inc.).

\section{Serologic testing}

After amplification of $E$. chaffeensis DNA from the mother's blood, her physician requested E. chaffeensis serology from a commercial laboratory (Quest Diagnostics, 
Table 1 Conventional PCR primer sequences and thermocycler conditions for assays used in this study

\begin{tabular}{|c|c|c|}
\hline Target gene & $\begin{array}{l}\text { Size in base } \\
\text { pairs (bp) }\end{array}$ & Primers names and sequence, reaction mix and run conditions \\
\hline \multirow[t]{2}{*}{$\begin{array}{l}\text { Ehrlichia or Anaplasma } \\
16 \mathrm{~S} \text { rRNA }\end{array}$} & $420 \mathrm{bp}$ & $\begin{array}{l}\text { GEPs 5' CTG GCG GCA AGC YTA ACA CAT GCA AGT CGA ACG GA 3' } \\
\text { GEPr 5' CTT CTT CTR TRG GTA CCG TCA TTA TCT TCC CYA YTG 3' }\end{array}$ \\
\hline & & $\begin{array}{l}\text { For } 25 \mu \mathrm{L} \text { mix: } 12.5 \mu \mathrm{L} \text { MyTaq HS mix (Bioline), } 0.2 \mu \mathrm{L} 100 \mu \mathrm{M} \text { each primer (IDT }{ }^{\oplus} \mathrm{DNA} \text { Technology), } 7.3 \mu \mathrm{l} \\
\text { molecular grade water, }+5 \mu \mathrm{l} \text { template DNA. Denaturation } 2 \text { min } @ 95^{\circ} \mathrm{C} \text {, then } 55 \text { cycles } 15 \mathrm{sec} @ 94^{\circ} \mathrm{C} \text {, } \\
\text { annealing } 10 \mathrm{sec} @ 64^{\circ} \mathrm{C} \text {, extension } 15 \mathrm{sec} @ 72^{\circ} \mathrm{C} \text {, final extension } 30 \mathrm{sec} @ 72^{\circ} \mathrm{C} \text {. }\end{array}$ \\
\hline \multirow[t]{2}{*}{$\begin{array}{l}\text { Ehrlichia or Anaplasma } \\
\text { 16S rRNA }\end{array}$} & 973 bp & $\begin{array}{l}\text { GEPs 5' CTG GCG GCA AGC YTA ACA CAT GCA AGT CGA ACG GA 3' } \\
\text { LongGEP1060r 5'CTG TGT RAG GTC CAG CCG AAC TGM SYC 3' }\end{array}$ \\
\hline & & As above except annealing and extension times extended to 25 and $30 \mathrm{sec}$ \\
\hline \multirow[t]{2}{*}{ Ehrlichia spp. sodb } & $300 \mathrm{bp}$ & $\begin{array}{l}\text { sodbF 5'- TाT AAT AAT GCT GGT CAA GTA TGG AAT CAT } \\
\text { sodbR 5'- AAG CGT GTT CCC ATA CAT CCA TAG }\end{array}$ \\
\hline & & $\begin{array}{l}\text { For } 50 \mu \mathrm{l} \text { mix: } 24 \mu \mathrm{l} \text { MyTaq HS Mix (2X) (Bioline), } 1 \mu \mathrm{l} 50 \mathrm{uM} \text { each primer (Sigma-Aldrich), } 4 \mu \mathrm{l} \text { molecular } \\
\text { grade water }+20 \mu \mathrm{l} \text { template DNA. Single hot start cycle } 3 \mathrm{~min} @ 95^{\circ} \mathrm{C} \text {, then } 55 \text { cycles denaturation } \\
10 \mathrm{sec} @ 94^{\circ} \mathrm{C} \text {, annealing } 15 \mathrm{sec} @ 58^{\circ} \mathrm{C} \text {, extension } 15 \mathrm{sec} @ 72^{\circ} \mathrm{C} \text {, then a single cycle } 30 \mathrm{sec} @ 72^{\circ} \mathrm{C} \text {. }\end{array}$ \\
\hline \multirow[t]{2}{*}{ E.chaffeensis p28 } & $590 \mathrm{bp}$ & $\begin{array}{l}\text { EchP28F 5'- GAC CCA ACA GGT AGT GGT ATT AAC GG } \\
\text { EchP28R 5'- CTG GGC TTA TAG AGT AGC TTA AAC CTA AC }\end{array}$ \\
\hline & & $\begin{array}{l}\text { For } 25 \mu \mathrm{L} \text { mix: } 12.5 \mu \mathrm{l} \text { MyTaq HS Mix (2X) (Bioline), } 0.25 \mu \mathrm{l} 50 \text { uM each primer (Sigma-Aldrich), } 7 \mu \mathrm{l} \\
\text { molecular grade water }+5 \mu \mathrm{l} \text { template DNA. Single hot start cycle } 3 \text { min @95 } 5^{\circ} \mathrm{C} \text {, then } 55 \text { cycles } \\
\text { denaturation } 15 \mathrm{sec} @ 94^{\circ} \mathrm{C} \text {, annealing } 15 \mathrm{sec} @ 58^{\circ} \mathrm{C} \text {, extension } 30 \mathrm{sec} @ 72^{\circ} \mathrm{C} \text {, then a single cycle } 30 \mathrm{sec} \\
@ 72^{\circ} \mathrm{C} \text {. }\end{array}$ \\
\hline \multirow[t]{2}{*}{ E. ewingii p28 } & $215 \mathrm{bp}$ & $\begin{array}{l}\text { EEM2F (Ref 32) 5'-GGA GCT AAA ATA GAA GAT AAT C } \\
\text { EEM1R 5'-GTG CCA AAA GGT AAT ACA T }\end{array}$ \\
\hline & & $\begin{array}{l}\text { For } 25 \mu \mathrm{l} \text { mix: } 12.5 \mu \mathrm{l} \text { of MyTaq HS Mix }(2 \mathrm{X}) \text { (Bioline), } 0.25 \mu \mathrm{l} 50 \mu \mathrm{M} \text { each primer (Sigma-Aldrich), } 2 \mu \mathrm{l} \\
\text { molecular grade water }+10 \mu \mathrm{l} \text { template DNA. Single hot start cycle } 3 \mathrm{~min} @ 95^{\circ} \mathrm{C} \text {, then } 55 \text { cycles } \\
\text { denaturation at } 15 \mathrm{sec} @ 94^{\circ} \mathrm{C} \text {, annealing } 15 \mathrm{sec} @ 56^{\circ} \mathrm{C} \text {, extension } 30 \mathrm{sec} @ 72^{\circ} \mathrm{C} \text {, then a single cycle } 1 \mathrm{~min} \\
@ 72^{\circ} \mathrm{C} \text {. }\end{array}$ \\
\hline \multirow[t]{2}{*}{ A. platys $\mathrm{p} 44$} & $520 \mathrm{bp}$ & $\begin{array}{l}\text { Apl_p44F3 5'- GCT AAG TGG AGC GGT GGC GAT GA CAG } \\
\text { Apl_p44R3 5'- CGA TCT CCG CCG CTT TCG TAT TCT TC }\end{array}$ \\
\hline & & $\begin{array}{l}\text { For } 25 \mu \mathrm{L} \text { mix: } 12.5 \mu \mathrm{l} \text { MyTaq HS Mix (2X) (Bioline), } 0.3 \mu \mathrm{l} 50 \mathrm{uM} \text { each primer (Sigma-Aldrich), } 2 \mu \mathrm{l} \\
\text { molecular grade water }+10 \mu \mathrm{l} \text { template DNA. Single hot start cycle } 3 \text { min @ } 95^{\circ} \mathrm{C} \text {, then } 55 \text { cycles } \\
\text { denaturation } 15 \mathrm{sec} @ 94^{\circ} \mathrm{C} \text {, annealing } 10 \mathrm{sec} @ 70^{\circ} \mathrm{C} \text {, and extension } 30 \mathrm{sec} @ 72^{\circ} \mathrm{C} \text {, then a single cycle } \\
1 \text { min @72 } 72^{\circ} \mathrm{C} \text {. }\end{array}$ \\
\hline
\end{tabular}

Nichols Institute, Valencia, CA); otherwise human serological testing was performed at the Rickettsial Disease Laboratory, UTMB. Serum specimens from all family members from multiple collection dates were serially diluted (twofold) from 1:64 to 1:2048 and tested for $E$. chaffeensis IgG class antibodies by ImmunoFluorescent assay (IFA) with Alexa Fluor 488 goat-anti-human secondary antibody (dilution 1:1000). An IFA titer of 1:64 or higher was considered positive. E. chaffeensis Western immunoblot was performed by SDS-PAGE using NUPAGE NoVEX 4-12\% polyacrylamide gels (Invitrogen, Carlsbad, CA). Separated proteins transferred to nitrocellulose membrane using a Trans-Blot SD Semi-Dry Electrophoretic Transfer Cell (Bio-Rad Laboratories, Hercules, CA) were blocked overnight with $5 \%$ nonfat dry milk (Bio-Rad) in $1 \mathrm{X}$ Tris-buffered saline (TBS) before incubation with serum samples diluted (1:100) in 5\% nonfat dry milk in $1 \mathrm{X}$ TBS overnight at room temperature. Blots were washed thoroughly then incubated with alkaline phosphatase labeled anti-human IgG ( $\gamma$ chain-specific) secondary antibodies and color reactions developed with BCIP/NBT phosphatase substrate (KPL, Inc. Gaithersburg, MD).
Serum from the dog was tested for Ehrlichia antibodies by IFA in the IPRL, using antigens derived from canine monocytic DH82 cultures infected with E. canis and E. chaffeensis and for Anaplasma or Ehrlichia antibodies using the Snap ${ }^{\oplus} \mathrm{Dx}^{\oplus}$, (IDEXX Laboratories Inc., Westbrook, Maine) $[19,20]$.

\section{Cell culture isolation}

Parallel isolation attempts were made using white blood cell pellets (WBC) into various cell lines at NCSU-IPRL and UTMB. EDTA anti-coagulated whole blood from each individual was lysed with either ACK lysis buffer or hypotonic saline and centrifuged at UTMB or centrifuged in two stages at IPRL to prepare WBC pellets which were suspended in medium and dispersed into $25 \mathrm{~cm}^{2}$ flasks containing DH82 and IES6 tick cells (IPRL) or DH82, RF/6A, Vero, HEL299 and C6/36 cells (UTMB) and incubated at $37^{\circ} \mathrm{C}$ in $5 \% \mathrm{CO}_{2}$. Negative control flasks were maintained in parallel. Cytology (Diff Quik or Gimenez staining) and PCR were sequentially performed. 


\section{Results}

\section{Exposure history}

The family resided in suburban Chicago. There were no forested areas that might contain tick-infested deer for at least 1 mile in any direction. The mother did not recall any tick infestations in the home before or after purchasing the puppy and no family member reported a history of tick attachment. Occasional raccoon, skunk, opossum, coyote and other small mammals and birds were seen in the neighborhood. The mother and daughter were the primary caregivers for the dog and the only family members to have experienced consistent dog contact and occasional bites.

\section{Bartonella serology and enrichment culture/PCR}

Based upon sequential testing, Bartonella spp. antibodies were not detected in the mother, daughter or dog's serum specimens, and at all testing time points, BAPGM enrichment blood culture platform specimens (4 PCRs/sample/ date of collection) were Bartonella sp. PCR negative. Thus, there was no serological or PCR evidence to support Bartonella spp. exposure or infection.

\section{Anaplasma/Ehrlichia conventional 16S rRNA PCR and sequencing}

Using $16 S$ GEP primers that amplify both Anaplasma and Ehrlichia species, Ehrlichia chaffeensis 165 rDNA was cPCR amplified and sequenced from one of three September 2011 blood specimens (Table 2). The $16 S$ rDNA sequence shared 99.7\% (359/360 base pair) similarity with $E$. chaffeensis strain Arkansas CP000236 (Table 3). Based upon this E. chaffeensis result, additional blood samples from the mother, dog, daughter, father and maternal grandmother were submitted for testing in the IPRL on five, four, three, two and one occasion, respectively between September 2011 and March 2012.
Beginning with the mother's December 2011 specimens, DNA was independently extracted from whole blood and WBC fractions from each family member in an effort to enhance $\mathrm{CPCR}$ sensitivity. By sequential testing, $E$. chaffeensis and E. ewingii $16 S$ rDNA (99.7\% similarity with NR044747) ehrlichiemia was documented in the dog, daughter and mother (Table 2). Also, at various time points, A. platys $16 S \mathrm{rDNA}(749 / 750 \mathrm{bp}, 99.9 \%$ similarity to M82801) was amplified and sequenced from the dog and mother's blood. Amplified Anaplasma and Ehrlichia DNA sequences shared between the dog, daughter and mother were identical.

\section{Anaplasma/ehrlichia p28, p44 and sodb gene amplification and DNA sequencing}

To confirm the $16 S$ rDNA PCR results, other Anaplasma and Ehrlichia spp. genes were targeted, using freshly extracted, stored, whole blood and WBC preparations. The initial A. platys, E. chaffeensis and E. ewingii DNA amplification results were confirmed by $\mathrm{cPCR}$ amplification and DNA sequencing of the $p 44, p 28$, and sodb genes (Table 3).

\section{Serology}

When tested by a commercial laboratory in February 2012, the mother was reportedly E. chaffeensis seroreactive (IgM < 1:40, IgG 1: 160); however, at UTMB, five sera collected between September 2011 and March 2012 (mother) and February and March (daughter) were not E. chaffeensis seroreactive at a 1:64 dilution by IFA testing. Western immunoblotting also did not identify Ehrlichia spp. antibodies. When tested by the IPRL in January 2012, the dog was not E. canis, Babesia canis, Babesia gibsoni, Bartonella henselae, Bartonella vinsonii subsp. berkhoffii, Leishmania infantum, or Rickettsia rickettsii IFA seroreactive and was also ELISA negative for Dirofilaria immitis

Table 2 Summary of conventional PCR amplification and DNA sequencing results from whole blood, serum, WBC fractions and DH82, RF/6A or IES6 cell cultures tested between September 2011 and June 2012

\begin{tabular}{|c|c|c|c|c|c|c|c|c|c|c|c|c|c|c|c|}
\hline \multirow[t]{2}{*}{ Date } & \multicolumn{3}{|c|}{ Mother } & \multicolumn{4}{|l|}{ Dog } & \multicolumn{4}{|c|}{ Daughter } & \multicolumn{4}{|c|}{ Father/Grandmother } \\
\hline & Ech & Eew & $A p l$ & Ech & Eew & Apl & $E c$ & Ech & Eew & Apl & $E c$ & $\overline{E c h}$ & Eew & Apl & Ec \\
\hline $09 / 2011$ & $+\#$ & - & - & NT & NT & NT & NT & NT & NT & NT & NT & NT & NT & NT & NT \\
\hline $12 / 2011$ & $+\#$ & $+^{*}$ & $+^{*}$ & $+\#$ & - & - & - & NT & NT & NT & NT & NT & NT & NT & NT \\
\hline $01 / 2012$ & $+\#$ & $+\#$ & $+\#^{*}$ & $+\#$ & - & $+\#^{*}$ & - & - & $+\#$ & - & - & NT & NT & NT & NT \\
\hline $02 / 2012$ & $+\#$ & $+\#$ & - & - & $+\#$ & $+^{*}$ & - & - & - & $+^{*}$ & - & - & - & - & - \\
\hline 03/2012 & $+^{*}$ & - & - & - & - & - & $t^{*}$ & $t^{*}$ & - & $+^{*}$ & - & - & - & - & - \\
\hline $06 / 2012^{* *}$ & - & - & - & - & - & - & - & - & - & - & - & NT & NT & NT & NT \\
\hline
\end{tabular}

Sample source or sources are designated for each testing time point.

Ech $=$ Ehrlichia chaffeensis, Eew $=$ Ehrlichia ewingii, Apl = Anaplasma platys, Ec $=$ Ehrlichia canis.

All + results confirmed by DNA sequencing.

\# = amplicon obtained from blood, serum or buffy coat fraction.

* = amplicon obtained from DH82, RF/6A or IES6 cell cultures.

$\mathrm{NT}=$ not tested.

${ }^{* *}=$ post doxycycline treatment. 
Table 3 Confirmation of conventional PCR amplification results by DNA sequencing of Ehrlichia and Anaplasma gene targets derived from blood or WBC samples from the mother, dog and daughter

\begin{tabular}{|c|c|c|c|c|c|c|c|c|c|}
\hline \multirow[t]{2}{*}{ Gene target $^{a}$} & \multicolumn{3}{|c|}{ Mother } & \multicolumn{3}{|c|}{ Daughter } & \multicolumn{3}{|l|}{ Dog } \\
\hline & Ech & Eew & Apl & Ech & Eew & Apl & Ech & Eew & Apl \\
\hline GEP $16 \mathrm{~S}$ & 99.7 & 99.7 & 99.9 & no & 99.7 & no & 99.7 & 99.7 & 99.9 \\
\hline $\operatorname{sod} B$ & 100 & 99.2 & NA & no & 100 & NA & 100 & no & NA \\
\hline P28 & 96.6 & 100 & NA & no & 100 & NA & 96.6 & no & NA \\
\hline P44 & NA & NA & 99.6 & NA & NA & no & NA & NA & 99.6 \\
\hline
\end{tabular}

Based upon DNA sequence similarities, specimens from the dog and both family members contained the same genotypes.

Ech $=$ Ehrlichia chaffeensis.

Eew $=$ E. ewingii.

Apl = Anaplasma platys

$\mathrm{NA}=$ not an applicable gene target for the particular Anaplasma or

Ehrlichia species.

${ }^{a}$ Numbers represent \% sequence identity to the following GenBank reference sequences: A. platys 165 M82801 from a dog, A. platys $p 44 \mathrm{GQ} 868750.1$ from a Venezuela dog strain, $E$. chaffeensis 165 CP000236, complete genome of an Arkansas human strain, $E$. chaffeensis sodB CP000236, E. chaffeensis p28 human strains V8 (AF393394.1) and V4 (AF393390.1), E. ewingii 16S Accession NR_044747 from an Oklahoma dog strain, E. ewingii sodB (GenBank KC778986) from a naturally-infected dog procured through our diagnostic laboratory and validated by other E. ewingii gene targets, and E. ewingii p28 AF287961.1 from a dog strain and AF287962.1, AF287963.1 and AF287966.1 from human strains.

antigen and Anaplasma spp., Borrelia burgdorferi C6 peptide, and Ehrlichia spp. antibodies.

\section{Cell culture isolation}

Organism isolation efforts at both NCSU and UTMB generated Diff Quik or Gimenez staining indications of intracellular bacteria or morulae, but did not result in successful isolation or evidence of organism amplification during 8-10 weeks in culture. Structures consistent with morulae were observed in the dog, daughter and mother's inoculated cell cultures, but not in the father, grandmother or un-inoculated control cell cultures. Anaplasma/Ehrlichia GEP $16 S$ cPCR amplified E. ewingii and A. platys from the dog, daughter and mother's IPRL DH82 cultures. E. chaffeensis DNA (16S rRNA, sodb, and $p 28$ ) was amplified from daughter and mother's UTMB RF/6A cultures. The dog and mother's E. chaffeensis $16 \mathrm{~S}$ rRNA, sodb sequences and $A$. platys $p 44$ sequences from cell culture were $100 \%$ identical to sequences previously amplifed from blood, serum or WBC specimens. The dog's March 2012 WBC inoculated DH82 (pid 8) and IES6 (pid 23) cell cultures yielded $16 \mathrm{~S} r R N A$ and sodb E. canis DNA.

\section{Treatment}

In May 2012, the mother was treated with doxycycline $100 \mathrm{mg}$ PO BID for 15 days and the dog was treated with doxycycline $5 \mathrm{mg} / \mathrm{kg}$ every 12 hours for 5 weeks. When retested in June 2012, blood and tissue culture cPCR results were negative and morulae-like structures were not visualized. The daughter was not treated.

\section{Discussion and conclusions}

This study provided PCR amplification and sequencing evidence supporting the persistence of A. platys, E. chaffeensis and E. ewingii DNA in the blood of a dog and two family members. Specifically, during the six month study period, E. chaffeensis, E. ewingii, and A. platys DNA was amplified and sequenced from the mother's blood and/or cell culture supernatant specimens at 5, 3, and 2 time points, respectively. Anaplasma and Ehrlichia gene targets not routinely assayed in our laboratory confirmed the initial identification of pathogen DNA in all three family members. Furthermore, the partial gene sequences amplified between family members were identical, suggesting they were infected with the same pathogen genotypes. Despite repeated molecular documentation of these bacteria, Ehrlichia spp. IFA antibody titers and Western immunobloting were negative at UTMB and the dog was not Anaplasma or Ehrlichia seroreactive at NCSU-IPRL. As A. platys and E. ewingii have not been successfully cultivated in cell culture, IFA serological assays were not available for testing purposes. Whether Anaplasma and Ehrlichia spp. co-infection altered the expected humoral immune response, whether assay antigens were not well matched with the infecting genotypes or whether anergy played a role in seronegativity remains unknown. Similar comparative correlations between canine and human vector-borne infections can be found in the literature. Persistent infections, spanning months to years, with $A$. platys, E. chaffeensis and E. ewingii, have been frequently reported in dogs $[6,7,18,21]$. In contrast, there is limited evidence supporting persistent human $E$. chaffeensis infections [10,11]. Based upon challenge studies, dogs can be experimentally re-infected with a homologous or heterologous $E$. canis isolate, thus infection does not infer protective immunity in dogs [22]. Re-infection with $E$. chaffeensis has also been reported in a liver transplant patient [23]. In conjunction with improved diagnostic testing modalities, co-infections of vector-borne diseases have been reported in dogs and in human patients. As dogs are more frequently exposed to ticks than their human counterparts, co-infections are more often reported in dogs [5-7,19] however, among other examples, E. chaffeensis and Rickettsia rickettsii co-infection was reported in a 44year-old man [24]. Experimentally, A. platys and E. canis co-infections in dogs [18], influenced the patterns and severity of hematologic and serologic findings.

To confirm and validate the initial, unexpected $16 \mathrm{~S}$ rDNA PCR results from the mother and subsequently the daughter and dog, other gene targets were amplified and sequenced, isolation was attempted in two laboratories, and two investigators tested samples independently and at different time points. Because microbial-specific genes were targeted, the same PCR assays are applicable for testing human and veterinary patient populations and vectors 
for the presence of bacterial DNA. PCR has limitations. False negative results occur when testing samples with low template concentrations and selective amplification of the predominant organism can occur in patients coinfected with genetically similar organisms. By comparing PCR results from different sample sources (blood, serum, buffy coat, and tissue culture extracts), the assays used in this study may not have been sensitive enough to consistently detect these bacteria within blood specimens collected during the same week (data not shown), illustrating the need to enhance the sensitivity of Anaplasma and Ehrlichia PCR, particularly when patient samples contain DNA sequences of genetically related organisms. DNA carryover or amplicon contamination within a laboratory may result in false positives [25,26]. Importantly, throughout this study, all DNA extraction and PCR-negative controls remained negative. Furthermore, PCR testing of blood, serum, WBC, and tissue culture extracts from the father or maternal grandmother did not identify Anaplasma and Ehrlichia sp. DNA, and both the dog and mother became PCR negative after treatment with doxycycline, a finding that supports infection with viable organisms.

Nearly two decades ago investigators in Venezuela described inclusions in human platelets, a subset of which were ultrastructurally consistent with $A$. platys $[27,28]$. Until recently [14], no subsequent report of human $A$. platys infection was published in the English literature. There is substantial epidemiological support for Rhipicephalus sanguineus (the brown dog or kennel tick) as the vector and the $\operatorname{dog}$ as the primary reservoir host for $A$. platys and E. canis [20]. As the puppy in this study originated from a kennel in Missouri, exposure to $R$. sanguineus seemed more likely than exposure to $A$. americanum, which is a field tick that will feed on numerous animal species [29]. Although vector competence has not been proven, $E$. chaffeensis DNA was amplified from $56 \%$ of $R$. sanguineus obtained from dogs and puppies housed in a kennel in Cameroon, a country where both canine and human infection with $E$. chaffeensis has been previously reported [30]. In contrast, recent efforts to experimentally transmit $E$. ewingii by $R$. sanguineus were not successful [31]. The source of $A$. platys, E. chaffeensis and E. ewingii infection in the pet and the family members and $E$. canis in the dog remains unknown; however, this puppy originated from a kennel in a highly endemic state for tick transmission of $E$. chaffeensis and E. ewingii by A. americanum $[1,29]$ and $A$. platys and $E$. canis are transmitted by a tick (R. sanguineus) that infests dogs in kennels.

In summary, A. platys and Ehrlichia spp. DNA was documented in an unusual familial cluster involving a dog and two family members. Future studies should determine whether repeated documentation of DNA of these organisms reflects ongoing infection and whether there are medical consequences associated with the persistence of
DNA of these organisms. To guide testing and treatment decisions, sequential PCR testing of blood, WBC or cell culture-enhanced samples may increase DNA-detection sensitivity.

\section{Abbreviations}

BAPGM: Bartonella alpha proteobacteria growth medium; EDTA: Ethylenediaminetetraacetic acid.

\section{Competing interests}

In conjunction with Dr. Sushama Sontakke and North Carolina State University, Dr. Breitschwerdt holds U.S. Patent No. 7,115,385; Media and Methods for cultivation of microorganisms, which was issued October 3 , 2006. He is the chief scientific officer for Galaxy Diagnostics, a company that provides advanced diagnostic testing for the detection of Bartonella species infection in animals and humans. All other authors have no potential conflict. In the context of this manuscript, none of the authors disclose any conflicts of interest.

\section{Authors' contribution}

EBB coordinated communications and generated the initial draft manuscript. $\mathrm{BCH}, \mathrm{BAQ}$, and RGM performed tissue culture isolation and PCR testing at North Carolina State University. TBS, LSB, and DHB performed tissue culture isolation and serological testing at the University of Texas Medical Branch at Galveston. All authors contributed to the content of the manuscript and all authors reviewed the final submission.

\section{Acknowledgements}

The authors would like to thank Dr. M. E. Dimperio, Park Ridge Animal Hospital, Park Ridge, IL 60068 and Dr. G. M. Trenholme, Rush University Medical Center, Chicago, IL 60612 for facilitating blood specimen collection from the pet dog and family members, respectively. We also thank the family members for providing and shipping blood to the IPRL and Department of Pathology, University of Texas Medical Branch, Galveston, Texas for testing purposes. We acknowledge Julie Bradley for technical assistance and Tonya Lee for editorial support.

\section{Source of funding}

Supported in part by the state of North Carolina, the Kindy French Foundation and an unrestricted donation from Bayer Animal Health to facilitate the study of zoonotic vector borne infectious diseases.

\section{Author details}

'Intracellular Pathogens Research Laboratory and the Center for Comparative Medicine and Translational Research, College of Veterinary Medicine, North Carolina State University, Raleigh, NC, USA. ${ }^{2}$ University of Texas Medical Branch, Galveston, TX, USA.

Received: 5 June 2014 Accepted: 23 June 2014 Published: 1 July 2014

\section{References}

1. Demma LJ, Holman RC, McQuiston JH, Krebs JW, Swerdlow DL: Epidemiology of human ehrlichiosis and anaplasmosis in the United States, 2001-2002. Am J Trop Med Hyg 2005, 73:400-409.

2. Nicholson WL, Allen KE, McQuiston JH, Breitschwerdt EB, Little SE: The increasing recognition of rickettsial pathogens in dogs and people. Trends Parasitol 2010, 26(4):205-212

3. Pritt BS, Sloan LM, Johnson DK, Munderloh UG, Paskewitz SM, McElroy KM, McFadden JD, Binnicker MJ, Neitzel DF, Liu G, Nicholson WL, Nelson CM, Franson JJ, Martin SA, Cunningham SA, Steward CR, Bogumill K, Bjorgaard ME, Davis JP, McQuiston JH, Warshauer DM, Wilhelm MP, Patel R, Trivedi VA, Eremeeva ME: Emergence of a new pathogenic Ehrlichia species, Wisconsin and Minnesota, 2009. N Engl J Med 2011, 365:422-429.

4. de Caprariis D, Dantas-Torres F, Capelli G, Mencke N, Stanneck D, Breitschwerdt EB, Otranto D: Evolution of clinical, haematological and biochemical findings in young dogs naturally infected by vector-borne pathogens. Vet Microbiol 2011, 149:206-212. 
5. De Tommasi AS, Otranto D, Dantas-Torres F, Capelli G, Breitschwerdt EB, de Caprariis D: Are vector-borne pathogen co-infections complicating the clinical presentation in dogs? Parasit Vectors 2013, 6:97.

6. Kordick SK, Breitschwerdt EB, Hegarty BC, Southwick KL, Colitz CM, Hancock SI, Bradley JM, Rumbough R, Mcpherson JT, MacCormack JN: Coinfection with multiple tick-borne pathogens in a Walker Hound kennel in North Carolina. J Clin Microbiol 1999, 37:2631-2638.

7. Breitschwerdt EB, Hegarty BC, Hancock SI: Sequential evaluation of dogs naturally infected with Ehrlichia canis, Ehrlichia chaffeensis, Ehrlichia equi, Ehrlichia ewingii, or Bartonella vinsonii. J Clin Microbiol 1998, 36:2645-2651.

8. Hegarty BC, Maggi RG, Koskinen P, Beall MJ, Eberts M, Chandrashekar R, Breitschwerdt EB: Ehrlichia muris infection in a dog from Minnesota. J Vet Intern Med 2012, 26:1217-1220.

9. Scorpio DG, Dumler JS, Barat NC, Cook JA, Barat CE, Stillman BA, DeBisceglie KC, Beall MJ, Chandrashekar R: Comparative strain analysis of Anaplasma phagocytophilum infection and clinical outcomes in a canine model of granulocytic anaplasmosis. Vector Borne Zoonotic Dis 2011, 11:223-229.

10. Dumler JS, Sutker WL, Walker DH: Persistent infection with Ehrlichia chaffeensis. Clin Infect Dis 1993, 17:903-905.

11. Roland WE, McDonald G, Caldwell CW, Everett ED: Ehrlichiosis: a cause of prolonged fever. Clin Infect Dis 1995, 20:821-825.

12. Perez M, Rikihisa $Y$, Wen B: Ehrlichia canis-like agent isolated from a man in Venezuela: antigenic and genetic characterization. J Clin Microbiol 1996, 34:2133-2139.

13. Unver A, Perez M, Orellana N, Huang H, Rikihisa Y: Molecular and antigenic comparison of Ehrlichia canis isolates from dogs, ticks, and a human in Venezuela. J Clin Microbiol 2001, 39:2788-2793.

14. Maggi RG, Mascarelli PE, Havenga LN, Naidoo V, Breitschwerdt EB: Coinfection with Anaplasma platys, Bartonella henselae and Candidatus Mycoplasma haematoparvum in a veterinarian. Parasit Vectors 2013, 6:103.

15. Pultorak EL, Maggi RG, Mascarelli PE, Breitschwerdt EB: Serial testing from a 3-day collection period by use of the Bartonella Alphaproteobacteria Growth Medium Platform may enhance the sensitivity of Bartonella species detection in bacteremic human patients. J Clin Microbiol 2013, 51(6):1673-1677

16. Maggi RG, Mascarelli PE, Pultorak EL, Hegarty BC, Bradley JM, Mozayeni BR, Breitschwerdt EB: Bartonella spp. bacteremia in high-risk immunocompetent patients. Diagn Microbiol Infect Dis 2011, 71:430-437.

17. Eddlestone SM, Diniz PPVP, Neer TM, Gaunt SD, Corstvet R, Cho D, Hosgood G, Hegarty B, Breitschwerdt EB: Doxycycline clearance of experimentally induced chronic Ehrlichia canis infection in dogs. J Vet Intern Med 2007, 21:1237-1242

18. Gaunt S, Beall M, Stillman B, Lorentzen L, Diniz P, Chandrashekar R, Breitschwerdt EB: Experimental infection and co-infection of dogs with Anaplasma platys and Ehrlichia canis: hematologic, serologic and molecular findings. Parasit Vectors 2010, 3:33.

19. Chandrashekar R, Mainville CA, Beall MJ, O'Connor T, Eberts MD, Alleman AR, Gaunt SD, Breitschwerdt EB: Performance of a commercially available in-clinic ELISA for the detection of antibodies against Anaplasma phagocytophilum, Ehrlichia canis, and Borrelia burgdorferi and Dirofilaria immitis antigen in dogs. Am J Vet Res 2010, 71:1443-1450.

20. Diniz PP, Beall MJ, Omark K, Chandrashekar R, Daniluk DA, Cyr KE, Koterski JF, Robbins RG, Lalo PG, Hegarty BC, Breitschwerdt EB: High prevalence of tick-borne pathogens in dogs from an Indian reservation in northeastern Arizona. Vector Borne Zoonotic Dis 2010, 10:117-123.

21. Eddlestone SM, Gaunt SD, Neer TM, Boudreaux CM, Gill A, Haschke E, Corstvet RE: PCR detection of Anaplasma platys in blood and tissue of dogs during acute phase of experimental infection. Exp Parasitol 2007, 115:205-210.

22. Breitschwerdt EB, Hegarty BC, Hancock SI: Doxycycline hyclate treatment of experimental canine ehrlichiosis followed by challenge inoculation with two Ehrlichia canis strains. Antimicrob Agents Chemother 1998, 42:362-368

23. Liddell AM, Sumner JW, Paddock CD, Rikihisa Y, Unver A, Buller RS, Storch GA: Reinfection with Ehrlichia chaffeensis in a liver transplant recipient. Clin Infect Dis 2002, 34:1644-1647.

24. Sexton DJ, Corey GR, Carpenter C, Kong LQ, Ghandi T, Breitschwerdt EB, Hegarty B, Chen SM, Feng HM, Yu XJ, Olano J, Walker DH, Dumler SJ: Dual infection with Ehrlichia chaffeensis and a spotted fever group rickettsia: a case report. Emerg Infect Dis 1998, 4:311-316.
25. Dong J, Olano JP, McBride JW, Walker DH: Emerging pathogens: challenges and successes of molecular diagnostics. J Mol Diagn 2008, 10:185-197.

26. Sontakke S, Cadenas MB, Maggi RG, Diniz PP, Breitschwerdt EB: Use of broad range16S rDNA PCR in clinical microbiology. J Microbiol Methods 2009, 76:217-225.

27. Arraga-Alvarado C, Montero-Ojeda M, Bernardoni A, Anderson BE, Parra O: Human ehrlichiosis: report of the 1st case in Venezuela. Invest Clin 1996, 37:35-49.

28. Arraga-Alvarado C, Palmar M, Parra O, Salas P: Fine structural characterization of a Rickettsia-like organism in human platelets from patients with symptoms of ehrlichiosis. J Med Microbiol 1999, 48:991-997.

29. Childs JE, Paddock CD: The ascendancy of Amblyomma americanum as a vector of pathogens affecting humans in the United States. Annu Rev Entomol 2003, 48:307-337.

30. Ndip LM, Ndip RN, Esemu SN, Walker DH, McBride JW: Predominance of Ehrlichia chaffeensis in Rhipicephalus sanguineus ticks from kennelconfined dogs in Limbe, Cameroon. Exp Appl Acarol 2010, 50:163-168.

31. Yabsley MJ, Adams DS, O'Connor TP, Chandrashekar R, Little SE: Experimental primary and secondary infections of domestic dogs with Ehrlichia ewingii. Vet Microbiol 2011, 150:315-321.

\section{doi:10.1186/1756-3305-7-298}

Cite this article as: Breitschwerdt et al:: Intravascular persistence of Anaplasma platys, Ehrlichia chaffeensis, and Ehrlichia ewingii DNA in the blood of a dog and two family members. Parasites \& Vectors 2014 7:298

\section{Submit your next manuscript to BioMed Central and take full advantage of:}

- Convenient online submission

- Thorough peer review

- No space constraints or color figure charges

- Immediate publication on acceptance

- Inclusion in PubMed, CAS, Scopus and Google Scholar

- Research which is freely available for redistribution 